\title{
PENGARUH BUDAYA ORGANISASI DAN MOTIVASI BERPRESTASI TERHADAP KINERJA DOSEN UNIVERSITAS RIAU KEPULAUAN BATAM TAHUN AKADEMIK 2014/2015
}

\author{
Dahrul Aman Harahap dan Rahmat Riyandi
}

\begin{abstract}
Abstrak
Banyak factor-faktor yang mempengaruhi kinerja dosen antara lain yaitu : budaya organisasi, kompetensi dosen, motivasi kerja dosen, pengalaman kerja, tingkat pendidikan, kesejahteraan, kepemimpinan dekan, persepsi dosen tentang manajemen dekan, supervisi dekan dan sebagainya. Agar penelitian dapat lebih focus dan mendalam, maka pada penelitian ini peneliti membatasi pada aspek budaya organisasi dan motivasi berprestasi terhadap kinerja dosen di Universitas Riau Kepulauan Batam tahun akademik 2014/2015.

Penelitian ini mempunyai tujuan sebagai berikut : 1) Untuk mengetahui pengaruh budaya organisasi terhadap kinerja dosen di Universitas Riau Kepulauan, Batam. 2) Untuk mengetahui pengaruh motivasi berprestasi organisasi terhadap kinerja dosen di Universitas Riau Kepulauan, Batam. 3) Untuk mengetahui pengaruh secara bersama sama budaya organisasi dan motivasi berprestasi terhadap kinerja dosen di Universitas Riau Kepulauan, Batam.

Penelitian ini akan dilaksanakan di Universitas Riau Kepulauan Batam Jl. Batu Aji Baru no. 99 Batam . Sedangkan waktu penelitian dilaksanakan $\underline{8}$ bulan yaitu AprilNopember 2015 Tahun Akademik 2014/2015.

Populasi dalam penelitian ini adalah semua dosen tetap yayasan yang ada di Universitas Riau Kepulauan Batam sebanyak 144 orang. Yang menjadi sampel adalah semua populasi dosen yang ada sebanyak 144 orang

Metode yang digunakan dalam penelitian ini adalah metode penelitian kuantitatif dengan pendekatan survey. Uji Validitas semua instrument dihasilkan probabilitas yang dihitung semua menunjukkan lebih kecil dari nilai probabilitas yang ditetapkan. (Sig. 2-tailed $\leq \alpha 0.05$ ) yang berarti semua butir pertanyaan valid dan nilai. Sedangkan hasil realibitas bahwa semua instrumen memiliki nilai koefisien reliabilitas (Cronach's Alpa) > 0,6 maka instrument memiliki reabilitas yang baik, atau dengan kata lain instrument adalah reliable atau terpercaya.

Hasil Penelitian menunjukan bahwa Variabel budaya organisasi (X1)memiliki t hitung $>\mathrm{t}$ tabel yaitu $1.963>1.66$ dan nilai sig yang diperoleh sebesar $0.015(0.05>0.015$ ). Varibel Motivasi Berprestasi (X2) bahwa t hitung > t tabel yaitu $10.491>1.66$ dan nilai sig yang diperoleh sebesar $0.000(0.05>0.000)$. Sedangkan uji F yakni dengan memandingkan nilai probabilitasnya, yakni proabilitas yang dihitung (Sig) dengan proabilitas yang ditetapkan yaitu sebesar 0,05 . Dari tabel pengolahan data dibawah terlihat bahwa nilai $F$ dengan probabilitas Sig $0,000<\alpha 0,05$. Dengan demikian Ho ditolak.

Kesimpulan dalam penelitian ini adalah bahwa variabel Budaya Organisasi (X1) berpengaruh positif dan signifikan terhadap Kinerja Dosen (Y). Variabel Motifasi Berprestasi (X2) berpengaruh positif dan signifikan terhadap Kinerja Dosen (Y).Sedangkan secara bersama-sama variabel Budaya Organisasi dan Motifasi berprestasi berpengaruh positif dan signifikan terhadap Kinerja Dosen Universitas Riau Kepulauan Batam
\end{abstract}

Kata Kunci : Budaya Organisasi, Motivasi Berprestasi, Kinerja Dosen 


\section{PENDAHULUAN}

\section{Latar Belakang Penelitian}

Keberadaan dosen sangat menentukan mutu pendidikan dan lulusan yang dilahirkan perguruan tinggi, di samping secara umum kualitas perguruan tinggi itu sendiri. Jika para dosennya berkinerja dan bermutu tinggi,maka kualitas perguruan tinggi tersebut juga akan tinggi, demikian pula sebaliknya. Sebaik apapun program pendidikan yang dicanangkan, bila tidak didukung oleh para dosen berkinerja dan bermututinggi, maka akan berakhir pada hasil yang tidak memuaskan. Oleh karenanya untukmenjalankanprogram pendidikan yang baik diperlukan para dosen yang juga bermutu tinggi. Dengan memiliki Dosen -dosen profesional dan bermutu tinggi, perguruan tinggi dapat merumuskan program serta kurikulum termodern sehingga dapat menjamin lahirnya lulusan-lulusan yang berprestasi dan berkualitas istimewa. Peran dosen pada dasarnya sangat kompleks tidak hanya mencakup tridharma perguruan tinggitapi lebih dari itu.

Keberhasilan suatu organisasi termasuk organisasi bidang pendidikan dalam mencapai tujuanya diantaranya sangat ditentukan oleh mutu kepemimpinan yang terdapat pada organisasi yang bersangkutan yang berhubungan dengan budaya organisasi, motivasi berprestasi, dan komitmen pada organisasi yang sangat dibutuhkan dalam mengarahkan kinerja para anggota organisasi, karena kinerja yang ditunjukkan oleh para anggota organisasi akan berdampak pada pencapaian tujuan organisasi secara keseluruhan. Motivasi merupakan salah satu alat atasan agar bawahan mau bekerja keras dan bekerja cerds sesuai dengan yang diharapkan.Pengetahuan tentang pola motivasi membantu para manajer memahami sikap pegawai masing-masing. Bawahan perlu dimotivasi karena ada bawahan yang baru mau bekerja setelah dimotivasi atasannya.

Rendahnya mutu lulusan Universitas Riau Kepulauan menimbulkan tudingan rendahnya kinerja dosen dan sarana prasarana yang mendukung dalam proses pendidikan itu sendiri, karena peran dosen sangat sentral untuk memotivasi dan mengarahkan mahasiswa untuk dapat belajar dengan baik. Dalam hal ini yang menjadi pertanyaan dalam lulusan yang kurang dapat berkompetisi ini adalah factorfaktor apa sajakah yang mempengaruhi kinerja dosen tetap yayasan sehingga muncul tudingan bahwa kesalahan terbesar adalah berada pada kinerja dosen yang rendah.

Beberapa factor factor yang sangat berpengaruh terhadap kinerja dosen, berdasarkan latar belakang di atas dapat diidentifikasi permasalahannya sebagai berikut: Bagaimana budaya organisasi di Universitas Riau Kepulauan, bagaimana motivasi berprestasi di Universitas Riau Kepulauan dan bagaimana kinerja dosen di Universitas Riau Kepulauan.

\section{Tujuan Penelitian}

Penelitian ini mempunyai tujuan sebagai berikut :

a. Untuk mengetahui pengaruh budaya organisasi terhadap kinerja dosen di Universitas Riau Kepulauan, Batam.

b. Untuk mengetahui pengaruh motivasi berprestasi organisasi terhadap kinerja dosen di Universitas Riau Kepulauan, Batam. 
c. Untuk mengetahui pengaruh secara bersama sama budaya organisasi dan motivasi berprestasi terhadap kinerja dosen di Universitas Riau Kepulauan, Batam.

\section{Kerangka Pikir/Paradigma}

Hubungan dari ketiga variable tersebut di atas dapat digambarkan seperti di bawah ini

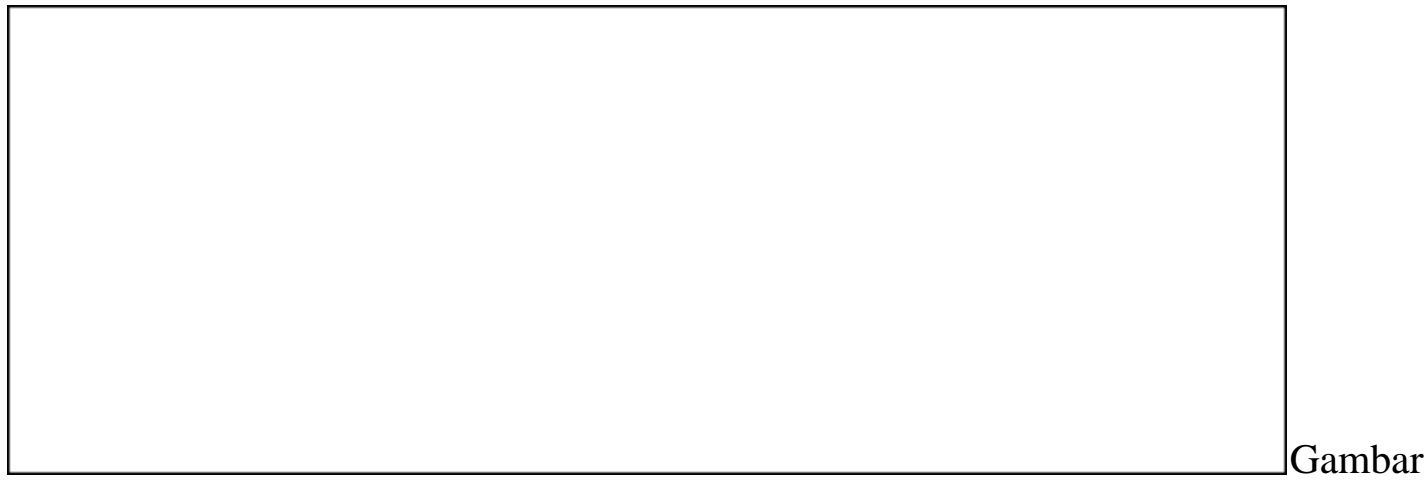

1. Kerangka berfikir

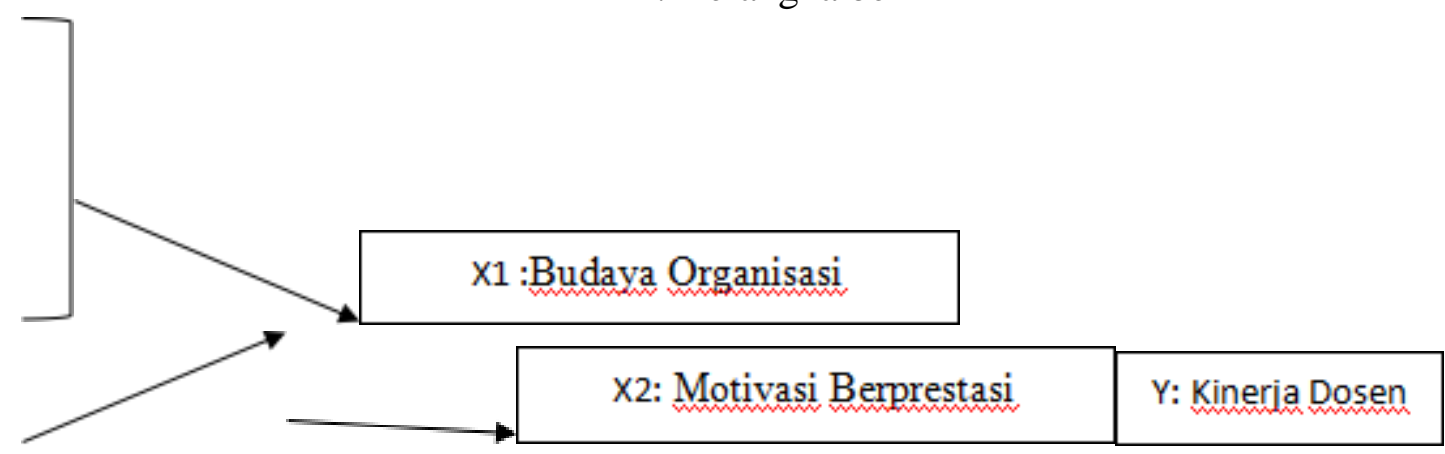

\section{Hipotesis Penelitian}

Adapun hipotesis yang diajukan dalam penelitian ini adalah sebagai berikut :

1. Secara parsial terdapat pengaruh yang positif dan signifikan budaya organisasi terhadap Kinerja Dosen

2. Secara parsial terdapat pengaruh yang positif dan signifikan motivasi berprestasi terhadap Kinerja Dosen

3. Secara bersama-sama terdapat pengaruh yang positif dan signifikan budaya organisasi, motivasi berprestasi terhadap Kinerja Dosen . 


\section{METODE PENELITIAN}

\section{Lokasi dan Waktu Penelitian}

Penelitian ini akan dilaksanakan di Universitas Riau Kepulauan Batam J1. Batu Aji Baru no. 99 Batam. Sedangkan waktu penelitian dilaksanakan $\underline{8}$ bulan yaitu AprilNopember 2015 Tahun Akademik 2014/2015.

\section{Populasi dan Sampel Penelitian}

Populasi dalam penelitian ini adalah semua dosen tetap yayasan yang ada di Universitas Riau Kepulauan Batam sebanyak 144 orang. Yang menjadi sampel adalah semua populasi dosen yang ada sebanyak 144 orang

\section{Jenis Penelitian}

Metode yang digunakan dalam penelitian ini adalah metode penelitian kuantitatif dengan pendekatan survey. Untuk mengolah dan menganalisis data-data yang terkumpul dilakukan dengan distribusi frekuensi, korelasi product moment, korelasi ganda, regresi linier sederhana dan regresi ganda. Pada penelitian ini dilakukan penelitian korelasi kuatnya hubungan antara variable bebas dengan variable terikat dengan metode analisis korelasi dan melakukan prediksi persamaan garis yang sesuai dengan analisis regresi linier (Sugiyono, $2004 ; 170$ )

\section{Variabel Penelitian}

Varibel penelitian ini terdiri dari dua jenis variable, variable bebas (independent variable), dan variable terikat (dependent variable). Penelitian ini terdiri 3 variabel yaitu dua variable bebas dan satu variable terikat. Variabel bebas yang pertama adalah budaya organisasi yang selanjutnya disebut $\mathrm{X} 1$, variable yang kedua motivasi berprestasi adalah yang selanjutnya disebut X2, sedangkan variable terikat 
adalah kinerja dosen Universitas Riau Kepulauan Batam yang selanjutnya disebut dengan Y.

\section{HASIL DAN PEMBAHASAN}

\section{Hasil Pengujian data \\ Hasil Uji Validitas Instrumen}

Setelah data penelitian yang berupa jawaban kuesioner dari responden penelitian dikumpulkan, selanjutnya dilakukan tabulasi data dan dilakukan pengujian terhadap kualitas data yang dikumpulkan tersebut. Uji kualitas data dilakukan dengan uji validitas dan reabilitas. Pengujian validitas butir pertanyaan pada kuisioner dilakukan dengan menggunakan SPSS versi 21. Nilai validitas butir pertanyaan dapat diketahui dengan cara melihat nilai Pearson Correlation positif dan Sig. 2-tailed $\leq \alpha$ 0.05. yang dapat dilihat pada lampiran Correlation X, X2 dan Y. Kriteria penarikan kesimpulan pengujian validitas adalah sebagai berikut (Rumengan, 2013):

1. Valid jika nilai probabilitas yang dihitung $\leq$ nilai probabilitas yang ditetapkan (Sig. 2tailed $\leq \alpha 0.05)$

2. Tidak valid jika nilai probabilitas yang dihitung $>$ nilai probabilitas yang ditetapkan (Sig. 2-tailed $\geq \alpha 0.05$ )

\section{a. Uji Validitas Budaya Organisasi (X1)}

Dari table 5.1 dapat dilihat bahwa butir pertanyaan X1.1 sampai dengan X1.20 probabilitas yang dihitung semua menunjukkan lebih kecil dari nilai probabilitas yang ditetapkan. (Sig. 2-tailed $\leq \alpha 0.05):$ X1.1-X1.20 $(0.000-0.040<0.05)$ yang berarti semua butir pertanyaan valid dan nilai korelasinya positif maka semua bisa dilanjutkan ke pengujian selanjutnya.

b. Uji Validitas Motivasi Berprestasi (X2)

Dari table 5.2 dapat dilihat bahwa dari butir pertanyaan X2.1 sampai dengan X2.20 probabilitas yang dihitung semua menunjukkan lebih kecil dari nilai probabilitas yang ditetapkan. (Sig. 2-tailed $\leq \alpha 0.05):$ X2.1-X2.20 $(0.000-0.025<0.05)$ yang berarti semua butir pertanyaan valid dan nilai korelasinya positif maka semua bisa dilanjutkan ke pengujian selanjutnya.

c. Uji Validitas Kinerja Dosen (Y)

Dari table 5.3 dapat dilihat bahwa dari butir pertanyaan Y1 sampai dengan Y25 probabilitas yang dihitung semua menunjukkan lebih kecil dari nilai probabilitas yang ditetapkan. (Sig. 2-tailed $\leq \alpha 0.05)$ : Y1-Y25 (0.000-0.046<0.05)yang berarti semua butir pertanyaan valid dan nilai korelasinya positif maka semua bisa dilanjutkan ke pengujian selanjutnya.

\section{Hasil Uji Reabilitas Instrumen}

Selain uji validitas, untuk pengujian kualitas data perlu juga dilakukan uji reabilitas data. Agar mengetahui sejauh mana hasil suatu pengukuran dapat dipercaya yang dilakukan 
dengan menggunakan teknik analisis Cronach alpha. Yaitu jika nilai koefisien reliabilitas (Cronach's Alpa) > 0,6 maka instrument memiliki reabilitas yang baik, atau dengan kata lain instrument adalah reliable atau terpercaya. (Rumengan, 2013).

\section{a. Uji Reabilitas Budaya Organisasi (X1)}

Dari tabel 5.4 dibawah diketahui bahwa hasil uji reabilitas budaya organisasi X1) adalah sebesar 0,737. > 0.6 maka hasil uji menunjukkan reabilitas yang baik, dengan kata lain instrument adalah reael atau terpercaya.

Tabel 5.4Uji Reabilitas Budaya Organisasi (X1)

Reliability Statistics

\begin{tabular}{|c|c|}
\hline Cronbach's Alpha & $\mathrm{N}$ of Items \\
\hline .737 & 21 \\
\hline
\end{tabular}

b. Uji Reabilitas Motivasi Berprestasi (X2)

Dari tabel 5.5 dibawah diketahui bahwa hasil uji reabilitas Motivasi Berprestasi ( $\mathrm{X} 2$ ) adalah sebesar 0,733 > 0.6 maka hasil uji menunjukkan reabilitas yang baik, dengan kata lain instrument adalah real atau terpercaya.

Tabel 5.5. Uji Reabilitas Motifasi Berprestasi (X2)

Reliability Statistics

\begin{tabular}{|r|r|}
\hline Cronbach's Alpha & N of Items \\
\hline .733 & 21 \\
\hline
\end{tabular}

\section{c. Uji Validitas Kinerja Dosen (Y)}

Dari tabel 5.6 dibawah diketahui bahwa hasil uji reabilitas Kinerja Dosen ( Y) adalah sebesar 0,746 > 0.6 maka hasil uji menunjukkan reabilitas yang baik, dengan kata lain instrument adalah reael atau terpercaya.

Tabel 5.6. Uji Reabilitas Kinerja Dosen (Y)

Reliability Statistics

\begin{tabular}{|c|c|}
\hline Cronbach's Alpha & $\mathrm{N}$ of Items \\
\hline .746 & 26 \\
\hline
\end{tabular}

\section{Uji Prasyarat Analsisi}

Sebelum dilakukan pengujian hipotesis maka harus kita lakukan terlebih dahulu pengujian asumsi klasik liner berganda yang dikenal pula dengan istilah BLUE (Best Linear Unbiased Estimation) yang meliputi pengujian linearitas, normalitas, multikolinearitas, heteroskedastisitas dan autokorelasi.

\section{Linearitas}

Menurut Rumengan (2013) bahwa pengujian lineritas digunakan untuk melihat apakah dalam model regresi, hubungan antar variabel adalah linear atau tidak. Kriteria penarikan kesimpulan adalah

1. Jika nilai linearity adalah signifikan $($ sig < 0.05$)$ maka hubungan adalah linear 
2. Jika nilai deviation from linearity adalah tidak signifikan ( $\operatorname{sig}>0.05)$ maka hubungan adalah linear.

\section{Uji Linearitas Budaya Organisasi (X1) Dengan Kinerja Dosen (Y)}

Dari Tabel 5.8 Dapat dilihat bahwa hubungan variabel Budaya Organisasi (X1) dengan Kinerja Dosen (Y) adalah Linear, karena nilai linearity adalah signifikan (Sig0.003<0.05) dan Nilai deviation from Linearity adalah tidak signifikan (Sig0.312>0.05).

Tabel 5.8. Uji Linearitas Budaya Organisasi (X1) Dengan Kinerja Dosen (Y)

\begin{tabular}{|c|c|c|c|c|c|c|c|}
\hline \multicolumn{8}{|c|}{ ANOVA Table } \\
\hline & & & Sum of Squares & $\overline{d f}$ & Mean Square & $\bar{F}$ & Sig. \\
\hline \multirow{5}{*}{$Y * X 1$} & \multirow{3}{*}{$\begin{array}{l}\text { Between } \\
\text { Groups }\end{array}$} & (Combined) & 4291.509 & 42 & 102.179 & 1.324 & 129 \\
\hline & & Linearity & 728.389 & 1 & 728.389 & 9.436 & .003 \\
\hline & & Deviation from Linearity & 3563.120 & 41 & 86.905 & 1.126 & .312 \\
\hline & \multicolumn{2}{|c|}{ Within Groups } & 7796.429 & 101 & 77.192 & & \\
\hline & \multicolumn{2}{|l|}{ Total } & 12087.937 & 143 & & & \\
\hline
\end{tabular}

\section{Uji Linearitas Motofasi Berprestasi (X2) Dengan Kinerja Dosen (Y)}

Dari Tabel 5.9 Dapat dilihat bahwa hubungan variabel Motifasi Berprestasi (X2) dengan Kinerja Dosen (Y) adalah Linear, karena nilai linearity adalah signifikan $(\operatorname{Sig} 0.000<0.05)$ dan Nilai deviation from Linearity adalah tidak signifikan (Sig0.595>0.05).

Tabel 5.9. Uji Linearitas Motofasi Berprestasi (X2) Dengan Kinerja Dosen (Y)

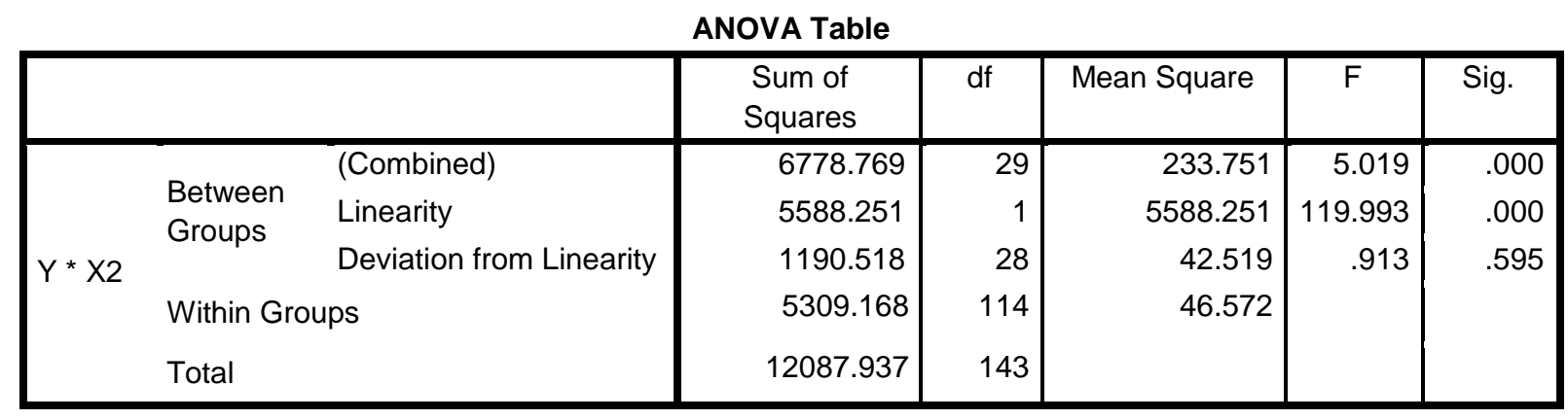

\section{Normalitas}

Berdasarkan hasil uji normalitas data dengan menggunakan grafik normal plot. Pada grafik 5.1 menunjukkan bahwa data (titik) menyebar di sekitar dan mendekati garis diagonal. Ini menunjukkan bahwa data penelitian yang mencakup variabel Budaya Organisasi, Motifasi berprestasi dan Kinerja Dosen telah menunjukkan distribusi data normal yang diperlukan sebelum melakukan pengujian hipotesis.

\section{Grafik 4.1. Uji Normalitas}




\section{Normal P.P Plot of Regression Standardized Residual}

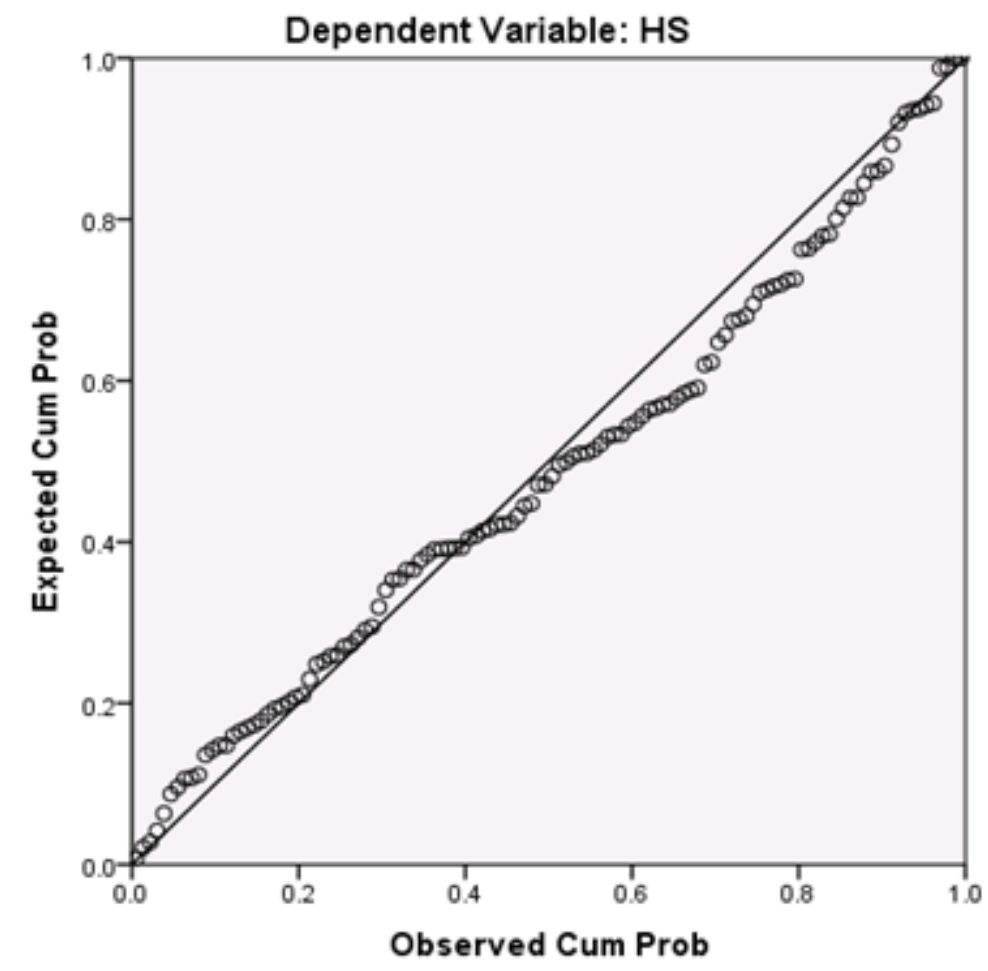

Sedangkan dengan menggunakan One sample Kolmogorov - smirnov Test. Kriteria penarikan kesimpulannya adalah data normal jika nilai Kolmogorov - smirnov adalah tidak signifikan (Asymp. Sig (2-tailed) $>\alpha 0.05$ ). Dari table 5.10 terlihat bahwa variabel X1 Asymp. Sig 0.426 > $\alpha$ 0.05, variabel X2 Asymp. Sig 0.207> $\alpha 0.05$, variabel Y Asymp. Sig $0.230>\alpha 0.05$. maka semua variabel tidak signifikan yang berarti data adalah normal.

Tabel 5.10

One Sample Kolmogorov - Smirnov Test One-Sample Kolmogorov-Smirnov Test

\begin{tabular}{|ll|r|r|r|}
\hline & & \multicolumn{1}{|c|}{ X1 } & \multicolumn{1}{|c|}{ X2 } & \multicolumn{1}{c|}{$\mathrm{Y}$} \\
\hline $\mathrm{N}$ & & 144 & 144 & 144 \\
Normal Parameters & Mean & 67.38 & 85.81 & 108.48 \\
& Std. Deviation & 12.088 & 6.856 & 9.194 \\
& Absolute & .073 & .089 & .087 \\
Most Extreme Differences & Positive & .073 & .063 & .058 \\
& Negative & -.053 & -.089 & -.087 \\
Kolmogorov-Smirnov Z & & .877 & 1.065 & 1.039 \\
Asymp. Sig. (2-tailed) & & .426 & .207 & .230 \\
a. Test distribution is Normal. & & & \\
b. Calculated from data. & & &
\end{tabular}

\section{Pembahasan}

\section{Signifikasi Budaya Organisasi (X1) Terhadap Kinerja Dosen (Y)}

Dari hasil pengujian di tabel 5.16 diketahui bahwa thitung > t tabel yaitu 1.963> 1.66 dan nilai sig yang diperoleh sebesar 0.015 ( $0.05>0.015$ ) yang berarti Budaya Organisasi berkontribusi secara signifikan terhadap Kinerja Dosen. Maka kesimpulannya adalah bahwa variabel Budaya Organisasi (X1) berpengaruh signifikan terhadap Kinerja Dosen (Y).dan 
dengan melihat tabel diatas bentukpersamaan regresi sederhana yang dihasilkan dari korelasi antar Budaya organisasi dengan Kinerja dosen adalah sebagai berikut:

$$
\mathrm{Y}=27.562+0.078 \mathrm{X} 1
$$

Konstanta sebesar 27,562 artinya walaupun variabel Budaya Organisasi bernilai 0 (nol) maka Kinerja Dosen tetap sebesar 27,562. Koefisien regresi sebesar 0.078 menyatakan bahwa setiap kenaikan satu nilai Budaya Organisasi memberikan kenaikan sebesar 0.078.

\section{Motifasi Berprestasi (X2) Terhadap Kinerja Dosen (Y)}

Dari hasil pengujian di tabel 4.14 diketahui bahwa t hitung > t tabel yaitu 10.491> 1.66 dan nilai sig yang diperoleh sebesar 0.000 ( $0.05>0.000$ ) yang berarti Motifasi Berprestasi berkontribusi secara signifikan terhadap Kinerja Dosen. Maka kesimpulannya adalah bahwa variabel Motifasi Berprestasi (X2) berpengaruh signifikan terhadap Kinerja Dosen (Y).Dan dengan melihat tabel diatas bentuk persamaan regresi sederhana yang dihasilkan dari korelasi antara Motivasi Berprestasi dengan Kinerja dosen adalah sebagai berikut:

$$
\mathrm{Y}=27.562+0.882 \mathrm{X} 2
$$

Konstanta sebesar 27,562 artinya walaupun variabel Budaya Organisasi bernilai 0 (nol) maka Kinerja Dosen tetap sebesar 27,562. Koefisien regresi sebesar 0.882 menyatakan bahwa setiap kenaikan satu nilai Motifasi Berprestasi memberikan kenaikan sebesar 0.882.

\section{Regresi Linear Berganda antara Budaya Organisasi (X1), Motifasi Berprestasi (X2) Terhadap Kinerja Dosen (Y)}

Untuk menguji hipotesis regresi berganda bisa dilakukan dengan uji $\mathrm{F}$ yakni dengan memandingkan nilai probabilitasnya, yakni proabilitas yang dihitung (Sig) dengan proabilitas yang ditetapkan yaitu sebesar 0,05. Dari tabel pengolahan data dibawah terlihat bahwa nilai $\mathrm{F}$ dengan probabilitas Sig $0,000<\alpha 0,05$. Dengan demikian Ho ditolak. Kesimpulannya adalah pengaruh Budaya Organisasi dan Motifasi berprestasi terhadap Kinerja Dosen adalah Signifikan.

ANOVA $^{\mathrm{a}}$

\begin{tabular}{|rl|r|r|r|r|r|}
\hline \multicolumn{1}{|l|}{ Model } & \multicolumn{1}{c|}{$\begin{array}{c}\text { Sum of } \\
\text { Squares }\end{array}$} & \multicolumn{1}{c|}{ Df } & \multicolumn{1}{c|}{$\begin{array}{c}\text { Mean } \\
\text { Square }\end{array}$} & F & Sig. \\
\hline \multirow{2}{*}{1} & Regression & 5708.469 & 2 & 2854.235 & 63.085 & $.000^{\mathrm{b}}$ \\
\cline { 3 - 6 } & Residual & 6379.468 & 141 & 45.244 & & \\
& Total & 12087.938 & 143 & & & \\
\hline
\end{tabular}

a. Dependent Variable: Y

b. Predictors: (Constant), X2, X1

Untuk memerikasa apakah model persamaan regresi linear yang terestimasi sudah cukup baik atau tidak. Atau dengan kata lain nilai R-square adalah untuk melihat bagaimana variasi nilai variable terikat dipengaruhi oleh variasi nilai variable bebas. Terlihat di bawah bahwa RSquare adalah 0,472 yang artinya Kinerja ditentukan oleh variable variable tersebut adalah 47,2\% sedangkan 52,8\% lagi ditentukan oleh variable lain. Dan terlihat bahwa adjusted R square adalah 0.465 yang artinya $46,5 \%$ berpengaruh terhadap kinerja sedangkan $53.5 \%$ ditentukan oleh variable lainnya. 
Model Summary ${ }^{\mathrm{b}}$

Tabel 5.15. R Square

\begin{tabular}{|l|r|r|r|r|}
\hline Model & R & R Square & Adjusted R Square & \multicolumn{2}{|c|}{$\begin{array}{c}\text { Std. Error of the } \\
\text { Estimate }\end{array}$} \\
\hline 1 & $.687^{\mathrm{a}}$ & .472 & .465 & 6.726 \\
\hline
\end{tabular}

a. Predictors: (Constant), X2, X1

b. Dependent Variable: Y

Analisis regresi dilakukan untuk menguji apakah variabel - variabel yang bersangkutan memiliki pengaruh signifikan atau tidak. Jika diperoleh nilai sig $=(0.05>$ nilai Sig) maka variabel tersebut memiliki pengaruh yang signifikan. Dan jika nilai sig $=(0.05<$ nilai sig) maka variabel tersebut tidak memiliki pengaruh signifikan.

Tabel 5.16.

\section{Model Persamaan Regresi Berganda}

Coefficients $^{\mathrm{a}}$

\begin{tabular}{|c|c|c|c|c|c|c|c|}
\hline \multirow[t]{2}{*}{ Model } & \multicolumn{2}{|c|}{$\begin{array}{l}\text { Unstandardized } \\
\text { Coefficients }\end{array}$} & \multirow{2}{*}{$\begin{array}{c}\text { Standardized } \\
\text { Coefficients }\end{array}$} & \multirow[t]{2}{*}{$\mathrm{t}$} & \multirow[t]{2}{*}{ Sig. } & \multicolumn{2}{|c|}{$\begin{array}{l}95.0 \% \text { Confidence } \\
\text { Interval for B }\end{array}$} \\
\hline & B & $\begin{array}{l}\text { Std. } \\
\text { Error }\end{array}$ & & & & $\begin{array}{l}\text { Lower } \\
\text { Bound }\end{array}$ & $\begin{array}{l}\text { Upper } \\
\text { Bound }\end{array}$ \\
\hline (Constant) & 27.562 & 7.251 & & 3.801 & .000 & 13.229 & 41.896 \\
\hline $1 \mathrm{X} 1$ & .078 & .048 & .102 & 1.963 & .015 & -.017 & .172 \\
\hline $\mathrm{X} 2$ & .882 & .084 & .658 & 10.491 & .000 & .716 & 1.048 \\
\hline
\end{tabular}

a. Dependent Variable: Y

Dari data diatas dapat dilakukan estimasi / prediksi, yakni dengan nilai - nilai di kolom Unstandardized Coefficients. Maka model persamaan regresinya adalah $\mathrm{Y}=\beta 0+\beta 1 \mathrm{X} 1+\beta 2 \mathrm{X} 2+\mathrm{e}$ $Y=27.562+0.078 X 1+0.882 X 2$.

\section{KESIMPULAN DAN SARAN}

\section{Kesimpulan}

Kesimpulan dalam penelitian ini adalah :

1. Budaya organisasi berpengaruh secara positif dan signifikan terhadap kinerja dosen .Artinya semakin baik budaya organisasi maka semakin baik kinerja dosen (searah).

2. Motivasi berprestasi berpengaruh secara positif dan signifikan terhadap kinerja dosen, Artinya semakin baik motivasi berprestasi maka semakin baik kinerja dosen (searah)

3. Budaya organisasi dan motivasi berprestasi berpengaruh secara positif dan signifikan terhadap kinerja dosen . Artinya jika semakin baik budaya organisasi dan motivasi berprestasi akan semakin meningkatkan kinerja dosen (searah).

\section{Saran}


Berdasarkan hasil penelitian, analisis data dan kesimpulan maka peneliti menyarankan:

1. Kepada pimpinan perguruan tinggi

Dalam peningkatan kinerja dosen harus mengembangkan ketrampilan manajerial dan strategi yang inovatif dalam menciptakan budaya organisasi yang sehat dan memotivasi agar dosen ikut termotivasi untuk berprestasi.

2. Kepada peneliti managemen pendidikan

Berharap agar peneliti atau calon peneliti dapat meneruskan dan mengembangkan penelitian untuk variabel lain yang sejenis untuk cakupan penelitian yang lebih luas atau dengan mengunakan pendekatan penelitian yang lain, sehingga dapat menambah wawasan dibidang managemen pendidikan.

\section{DAFTAR PUSTAKA}

Danim, sudarwan, 2012. Kepemimpinan Pendidikan : Kepemimpinan Jenis ( IQ + EQ ), Etika, Perilaku Motivasional, dan Mitos. Alfabeta, Bandung.

Prawironegoro, Darsono, 2010. Budaya organisasi.Nusantara Consulting, Jakarta.

Rahmawati,2013.Pengaruh budaya organisasi, gaya kepemimpinan, dan motivasi kerja terhadap kinerja dosen di universitas sultan ageng tirtayasa Universitas Sultan Ageng Tirtayasa. http://ejurnal.fisip-untirta.ac.id/. Diunduh 2 Feb 2014.

Rifai, Muhamad. 2009. Hubungan antara Gaya Kepemimpinan, Budaya Organisasi, Motivasi Berprestasi, dan Komitmen pada Organisasi, dengan Kinerja Dosen pada Universitas dalam Pesantren di Jawa Timur. Disertasi, Program Studi Manajemen Pendidikan, Program Pascasarjana, Universitas Negeri Malang.http://library.um.ac.id/freecontents/index.php/pub/detail/hubungan-antara-gaya-kepemimpinan-budayaorganisasi-motivasi-berprestasi-dan-komitmen-pada-organisasi-dengan-kinerja-dosenpada-universitas-dalam-pengelolaan-pesantren-di-jawa-timur-muhamad-rifai38479.html. Diunduh 3 feb 2014.

Rivai, Veithzal, 2005. Performance Appraisal.Jakarta : PT Raja Grafindo Persada.

Sugiyono, 2008.Metode Penelitian Bisnis; Pendekatan Kuantitatif, Kualitatif dan R\&D. Cv. Alfabeta, Bandung.

Robbins, Stephen P. andCoulter, Mary. 2010. Manajemen ; Edisi 10 Jilid 1. Alih Bahasa Bob Sabran dan Devri Barnadi Putra. Penerbit Erlangga, Jakarta.

Siagian, Sondang P., 2012. Teori Motivasi dan Aplikasinya. Rineka Cipta, Jakarta.

Sutrisno, Edy, 2011. Budaya organisasi. Kencana, Jakarta. 
Usman, Husaini, 2011. Manajemen ; Teori, Praktik, dan Riset Pendidikan. Bumi Aksara, Jakarta. 